\title{
Retraction Note: Observing the result of external magnetic field with nonextensivity on DA waves for two temperature electrons in a dusty plasmas
}

\author{
M.S. Zobaer • N. Roy • A.A. Mamun
}

Received: 6 March 2014 / Accepted: 6 March 2014 / Published online: 15 March 2014

(C) Springer Science+Business Media Dordrecht 2014

Retraction to: Astrophys Space Sci (2014) 350:231-236

DOI 10.1007/s10509-013-1746-1

This paper has been retracted by the authors on the grounds of honest error, in that their paper is missing a vital part of the analysis.

The online version of the original article can be found under doi:10.1007/s10509-013-1746-1.

M.S. Zobaer

Department of Applied Science, Bangladesh University

of Textiles, Tejgaon, Dhaka 1208, Bangladesh

N. Roy $(\varangle)$

United International University, Dhanmondi, Dhaka, Bangladesh

e-mail: niparoybd@yahoo.com

A.A. Mamun

Department of Physics, Jahangirnagar University, Savar,

Dhaka 1342, Bangladesh 